\title{
Lost in Translation? Students and the Hitches of Machine Translation of Academic Texts: Lecturers' Perspectives
}

\author{
Christian Atabong Nchindia ${ }^{1, *} \&$ Elizabeth Bennett ${ }^{1}$ \\ ${ }^{1}$ School of Education and Professional Development, University of Huddersfield, England, \\ United Kingdom \\ *Corresponding author: University of Huddersfield, 10 Queensgate, HD1 3DH Huddersfield, \\ United Kingdom. E-mail: Christian.AtabongNchindia@hud.ac.uk
}

Received: February 10, 2021 Accepted: March 16, 2021 Published: March 20, 2021

doi:10.5296/ije.v13i1.18289 URL: https://doi.org/10.5296/ije.v13i1.18289

\begin{abstract}
Machine translation (MT) of academic texts is a trending phenomenon in the higher education context. Globalisation and internationalisation have seen a massive number of foreign students being admitted into higher education in countries where they study in the second or target language. Some of these students find it challenging to write a good academic text in the second language (i.e., English in the case of the United Kingdom). As a remedy, they resort to translating their work from the source text (ST) to the target text (TT) using MT like Google or Bing translation. Although some research has shown that these devices can be beneficial, others have found that these devices are far from being perfect and can produce texts that distort the intended meaning. In addition, research into MT in educational contexts have overlooked the views of lecturers who are the ones that read and assess students' texts. This study aimed to contribute to the literature on MT by sampling the views of four academics from four different universities in the North West of England, United Kingdom. The findings of this research revealed that lecturers were very critical of students' usage of MT of academic texts. Among the reasons advanced for this rejection were that students were 'lost in translation' using MT, and that MT did not help non-English speaking students learn the language. Consequently, students can produce texts that could negatively affect their grades when assessed. This paper has made some policy recommendations to universities regarding the problems of MT and submitted suggestions for further research in this area.
\end{abstract}

Keywords: machine translation, source text, target text, higher education, google translation 


\section{Introduction}

Translation is the changing of an original text, known as the source text (ST), from the source language (SL) into a different language known as the target language (TL) or target text (TT) (Munday, 2016). Thus, when translating a text from Spanish to English, for instance, the ST is Spanish, and the TT is English. The theory, practice, and writing on translation can be traced far back in recorded history. For example, Nida (1964) wrote on the science of translating, and the theory and practice of translation (Nida \& Taber, 1969), Werner (1995) elucidated the concept of equivalence and the object of translation studies, while Pym (2007) examined the natural and directional equivalence in theories of translation. The writings of these scholars were largely focused on the 'traditional' form of translation done by human agents. With the advent of the computer and subsequently the internet, translation, and translation studies took a new twist, as both researchers and practitioners in the field adapt to the new reality. There is an increasing number of publications explaining the mechanics and operation of new technologies in this new environment (Bowker \& Fisher, 2010; Munday, 2016; Rensburg et al, 2012;). Examples of the new technological tools used for translation are Computer-assisted translation (CAT) and Machine translation (MT). Whilst CAT, which is mostly used by professional translators helps with the alignment of ST-TT pairs, MT tools can be used to generate automatic translations (Hartley, 2009), and are mostly used by nonprofessionals. Some of the most frequently used MT tools are free online instruments such as Bing translator, Google translate, and SYSTRAN (Hartley, 2009). In this paper, MT is examined as an individual practice at a non-professional level.

Globalisation and internationalisation have seen a massive number of foreign students being admitted into higher education in countries where they study in the second or target language. To some students, writing a piece of academic essay in the target language can be very challenging. Thus, they may resort to machine translation like Google translate and Bing to change their texts from ST to TT. A few scholars (Lee \& Briggs, 2021; Stander, 2020; Waddington, 2001) have studied the effects and impact of using machine translation, methods of evaluating, and strategies for helping students successfully use MT. These studies have overwhelming concentrated on the producers of the TT (i.e., the students), while neglecting the consumers of these texts (i.e., teachers or lecturers). This paper aims to add voice to the growing literature around student usage of MT by analysing the perspectives of four university lecturers in the UK on the use of machine translated texts by their students. Drawing on Bar-Hill (1959), Hatim and Munday (2004) assert that it is impossible for machines to replicate human translators as the former lacks real-world knowledge necessary for translation. Therefore, it is impossible for MT to reproduce the type of quality translation that a professional translator can produce. Some of the obstacles encountered by MT are sentences with multiple grammatical structures, uncertainty about what a pronoun refers to, words with multiple meanings, and other problems of grammar (Hatim \& Munday, 2004; Kay, 1997). When students translate academic texts using MT and these problems emerge, their grades and consequently, their academic achievement could be adversely affected if the problems are not resolved. Two research questions were formulated to guide our understanding of lecturers' perspective of the phenomenon of MT by students. 
a. How does MT affect students' academic writing?

b. What can be done to redress the problems arising from students' use of MT?

\section{Literature Review}

There are growing number of publications on the phenomenon of Machine translation made possible by modern technologies. A few of them that specifically focus on education are examined here. Groves and Mundt (2014) argue that MT will continue to improve and will have a profound positive influence for both students and academics. They reached this conclusion following a study where students were asked to submit an essay in their first language, and this was then translated into English through a web-based translation engine. After analysing the resulting English text for grammatical errors, they found that the MTs produced some errors. Despite these errors, the authors insisted that the level of accuracy from the MTs was approaching the minimum needed for university admission in many institutions (Groves \& Mundt, 2014).

Zhao et al. (2018) conducted a study on how to incorporate computer-supported collaborative learning into translation instruction. The study, which was conducted in China, examined the effects of using a social annotation tool to encourage student interaction during translation activities. They found that there was a positive impact on students' learning when they work on their translations in a social annotation supported environment (Zhao et al, 2018). Similarly, Kallkvist (2013), found potential for student agency in her study of translation tasks performed in a Swedish university setting. The mixed-method study suggests that translation may have potential to engender student activity because of the relatively strong presence of student-initiated interaction. The teacher also employed translation to create a forum for student-centred discussions in the course.

Furthermore, in a bid to help reduce plagiarism in a South African university, Stander (2020) conducted a study in which translation was employed as an intervention strategy. The study was intended to test whether translation would reduce plagiarism among first year university students. 73 BSc students who used English as a second language were sampled for the quantitative study. Students were asked to translate and then paraphrase texts in their own words which was later run through Turnitin for plagiarism detection. The author claimed that his findings proved that, if done correctly, translation (especially back translation) can facilitate text comprehension and consequently avoid plagiarism (Stander, 2020).

Lee (2020) studied the impact of using MT on English as a Foreign Language (EFL) for students at a Korean university. Thirty-four students were sampled in a mixed-method approach. The students were asked to translate their ST writing into TT without the help of MT and then correct their TT writing using the MT translation for comparison. The findings suggest that MT helped to decrease lexical and grammatical errors and improved student revisions. The study also found that MT can be useful in language learning, but teachers must provide adequate guidance to students to mitigate its limitations. These findings seem to support that of Zanettin (2009) who conducted a similar study in Italy. In that research, 
students were asked to revise an MT translation of a short text from an academic or journalistic source, and then write an essay explaining how they used corpora and corpus linguistics techniques to evaluate and revise the translation (Zanettin, 2009). The result of Zanettin's study found that this method of using MT benefited language learners.

Despite the many advantages of MT projected in the literature, studies have equally shown that MTs are far from being perfect (Groves \& Mundt, 2014), as they still cannot produce error-free texts. Kay (1997) argued that no translation system can translate pronouns or any other isolated words, and that MT lacks knowledge of the real-world which is essential for effective translation. Despite its complexity, MT is still unable to handle all types of text reliably and accurately (Hatim \& Munday, 2004), making human post-editing inevitable. Post-editing after MT itself is time-consuming and there has been a recent surge of interest in post-editing among the wider user community (O'Brien et al, 2014). Another major issue with machine translation is that of equivalence. This relates to equivalent items in specific ST-TT pairs and contexts (Werner, 1995). This is the relationship between source text and target text described in terms of their likeness, similitude, or sameness. Werner (1995) differentiates between five types of equivalence, namely:

1. Denotative equivalence (also known as content variant) related to equivalence of the extralinguistic content of a text.

2. Connotative equivalence (also known as stylistic equivalence) related to lexical choices, especially between near synonyms.

3. Text-normative equivalence, related to text types, with different kinds of texts behaving in different ways.

4. Pragmatic equivalence (also known as communicative equivalence) is oriented towards the receiver of the text or message.

5. Formal equivalence (also referred to as expressive equivalence) related to the form and aesthetics of the text, includes wordplays and the individual stylistic features of the ST. (Werner, 1995, cited by Munday, 2016, p. 75).

In addition to the equivalence issues, any good translation should be easy to read in the TT and the reader should hardly realise that he or she is reading a translated text. This "implies that all formulaic and idiomatic expressions should be rendered appropriately" (Poibeau, 2017, p. 10). It is unimaginable that MT can navigate through these complex set equivalences, and therefore, safe to say that the objective of a fully automatic machine translation which can replace human translators remains elusive. If the goal MT is to obtain a quality of translation equivalent to that of a human being, then such a goal is still at its infancy. This is because the quality of a translation is related to the nature and complexity of the text to be translated (Poibeau, 2017) which is too hard to formalise for automatic systems. 


\section{Methodology}

The data for this paper were extracted from data collected for another study by the same researcher (i.e., Nchindia, 2020) which both constituted data for a pilot study. The original study involved five lecturers who spoke about their experiences in intercultural interaction with students in UK universities. 2400 words of data related to the phenomenon of students translating academic texts were retrieved which derived from four of the five interviewees. Three of the lecturers were male and one was female, all between the ages of 40 and 60 at the time of the interviews in 2018. One was originally from Britain and the other three from Commonwealth countries that speak English either as a first or a second language. They taught different subjects in four separate universities in the North West of England, United Kingdom. They taught law, nursing, construction engineering, and business management. For privacy and confidentiality, the names and university of the participants have been anonymised, and the names used herein are pseudonyms. Two of the four participants were recruited through convenience sampling, one through purposive sampling and one through snowballing. The convenience samples were available by virtue of their accessibility (Bryman, 2004). This implies that the sample was easily accessible, was a close friend to the researcher, and was readily available to participate. The purposive sample was selected in terms of criteria that allowed the research questions to be answered (Bryman 2016), and the privilege knowledge that the unit held about the topic. The snowballed sample was put in contact with the researcher by one of the already recruited participant (David and Sutton 2004). Three interviews were conducted in the participants' offices at the university while one was done at the participant's home. All participants signed an informed consent form, prior to the interview, after reading the participant information sheet which gave details of the research. The interviews were audio-recorded, and the data was manually transcribed at the earliest opportunity. The transcripts were securely saved in a passworded protected account where only the researcher had access to. All ethical procedures were followed in line with the British Educational Research Association's (BERA, 2018) guidelines, the Data Protection Act (1998), and the General Data Protection Regulations (GDPR, 2018).

\section{Data Analysis}

Table 1. Number of Coded References per Case

\begin{tabular}{ccccc}
\hline Name & Files & References & Modified on & Modified by \\
\hline Dr Evelyn & 1 & 11 & $26 / 01 / 202113: 07$ & $\mathrm{CN}$ \\
Dr Julius & 1 & 16 & $26 / 01 / 202120: 14$ & $\mathrm{CN}$ \\
Dr Linus & 1 & 14 & $26 / 01 / 202120: 14$ & $\mathrm{CN}$ \\
Prof. Felix & 1 & 9 & $26 / 01 / 202114: 09$ & $\mathrm{CN}$ \\
\hline
\end{tabular}

Nvivo 12 software was employed for coding and thematic analysis. First, the transcript was uploaded to the software and themes emerged from the interpretation of the data as the coding process unfolded. Each of the four interviewees was coded as a 'case' and each 
coding reference was associated with the case who provided that specific data. The table below shows the total number of references coded for each case.

The 'explore' option of Nvivo was used to compare codes, compare cases, and conduct a cluster analysis. The comparison between codes and cases, using Pearson correlation coefficient revealed a significant, moderate, and poor correlation across cases as shown on the table below. The table below highlights a strong correlation between Dr Linus and Dr Evelyn as their coefficient value lies between 0.5 and 1 . There was a moderate correlation between Prof. Felix and Dr Evelyn, Prof. Felix and Dr Linus, and Dr Julius and Dr Evelyn as their coefficient value were between 0.30 and 0.49 . Lastly, there was a poor correlation in data between Dr Linus and Dr Julius, and Prof. Felix and Dr Julius as their coefficient value were below 0.29 . This analysis points to a strong convergence in the opinions expressed by most of the interviewees which goes to strengthen the trustworthiness of the conclusions reached in this study.

Table 2. Comparison across Cases Based on Coded Data

\begin{tabular}{llc}
\hline Code A & Code B & Pearson correlation coefficient \\
\hline Cases $\backslash \backslash$ Dr Linus & Cases $\backslash \backslash$ Dr Evelyn & 0.538426 \\
Cases $\backslash \backslash$ Prof. Felix & Cases $\backslash \backslash$ Dr Evelyn & 0.452801 \\
Cases $\backslash \backslash$ Prof. Felix & Cases $\backslash \backslash$ Dr Linus & 0.427401 \\
Cases $\backslash \backslash$ Dr Julius & Cases $\backslash \backslash$ Dr Evelyn & 0.333104 \\
Cases $\backslash \backslash$ Dr Linus & Cases $\backslash \backslash$ Dr Julius & 0.289254 \\
Cases $\backslash \backslash$ Prof. Felix & Cases $\backslash \backslash$ Dr Julius & 0.244228 \\
\hline
\end{tabular}

A chart and a table were produced that classified coded themes and cases according to their percentage coverages. The figure and table below give a visual and tabula representation of all coded themes, cases, and percentage coverages of the data. The data indicate that in terms of quantity, Dr Julius and Dr Linus provided more data at $23.91 \%$ and $20.63 \%$ respectively, as compared to Dr Evelyn, 13.22\% and Prof. Felix, 10.20\%. The percentage coverages by themes are also indicated. 


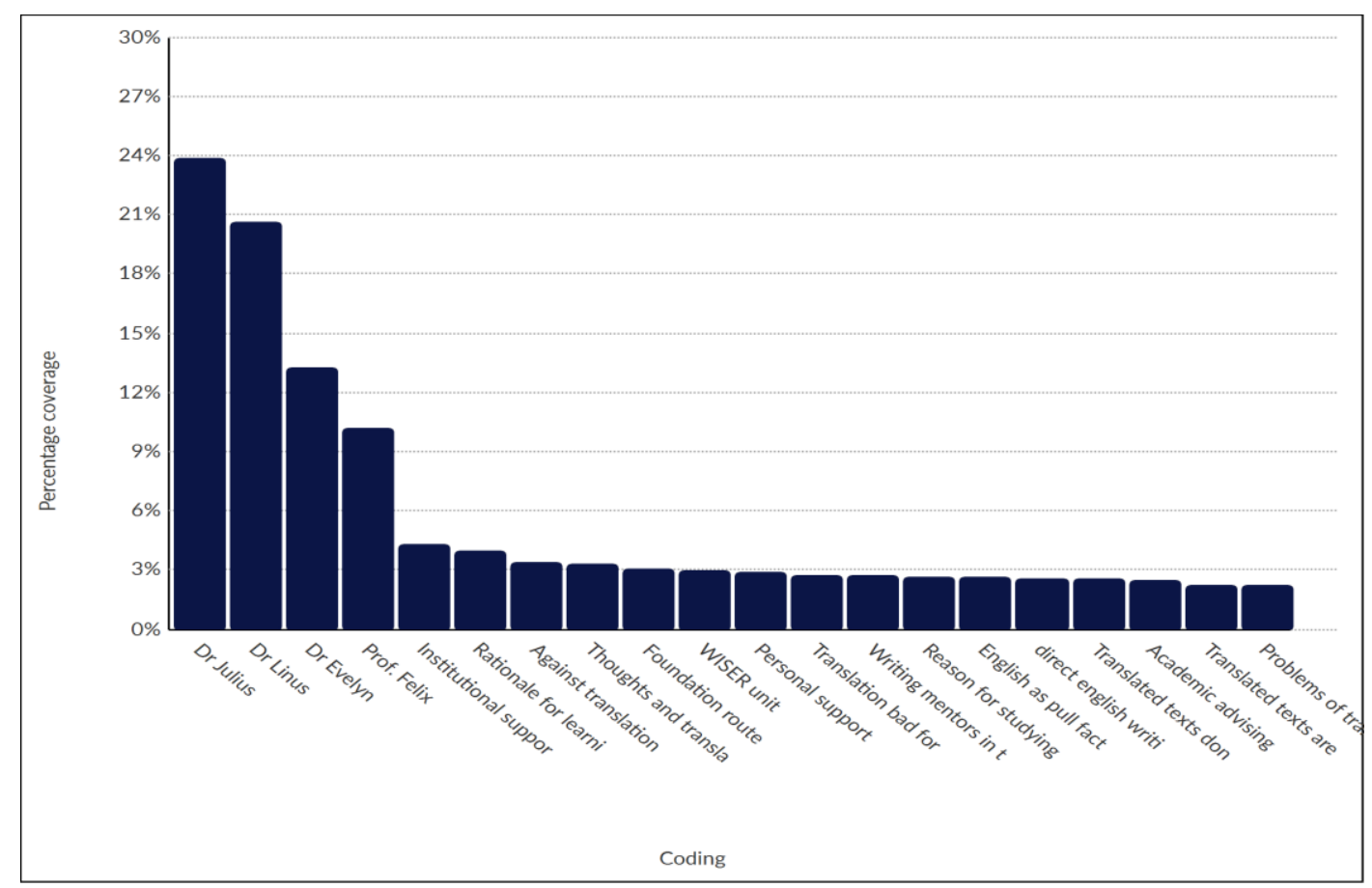

Figure 1. Chart Showing Coded Cases, Themes, and Percentages

Table 3. Coded Themes, Cases, and Percentages

\begin{tabular}{|c|c|}
\hline Coding & Percentage coverage \\
\hline Cases $\backslash \backslash$ Dr Evelyn & $13.22 \%$ \\
\hline Cases $\backslash \backslash$ Dr Julius & $23.91 \%$ \\
\hline Cases $\backslash \backslash$ Dr Linus & $20.63 \%$ \\
\hline Cases $\backslash \backslash$ Prof. Felix & $10.20 \%$ \\
\hline Codes $\backslash \backslash$ Against translation & $3.41 \%$ \\
\hline Codes $\backslash \backslash$ English as pull factor for foreign students & $2.67 \%$ \\
\hline Codes $\backslash$ Institutional support & $4.34 \%$ \\
\hline Codes $\backslash \backslash$ Institutional support|Foundation route & $3.05 \%$ \\
\hline Codes $\backslash \backslash$ Institutional support $\backslash W I S E R$ unit & $2.98 \%$ \\
\hline Codes $\backslash \backslash$ Institutional support $\backslash W$ riting mentors in the library & $2.72 \%$ \\
\hline Codes $\backslash \backslash$ Personal support & $2.92 \%$ \\
\hline Codes $\backslash \backslash$ Personal support $\backslash A$ cademic advising & $2.48 \%$ \\
\hline Codes $\backslash \backslash$ Problem of equivalence $\backslash$ Problems of translation-double tasks & $2.20 \%$ \\
\hline $\begin{array}{l}\text { Codes } \backslash \text { Problem of equivalence } \backslash \text { Problems of translation-double } \\
\text { tasks } \backslash \text { Translated texts do not make sense }\end{array}$ & $2.59 \%$ \\
\hline $\begin{array}{l}\text { Codes } \backslash \backslash \text { Problem of equivalence } \backslash \text { Problems of translation-double } \\
\text { tasks } \backslash \text { Translated texts do not make sense } \backslash \text { Translated texts are obvious }\end{array}$ & $2.20 \%$ \\
\hline Codes $\backslash \backslash$ Rationale for learning English & $3.95 \%$ \\
\hline Codes $\backslash \backslash$ Reason for studying in the UK & $2.67 \%$ \\
\hline Codes $\backslash \backslash$ Reason for studying in the UK\direct English writing helps & $2.59 \%$ \\
\hline Codes $\backslash \backslash$ Thoughts and translation & $3.35 \%$ \\
\hline Codes $\backslash \backslash$ Translation bad for academic writing & $2.78 \%$ \\
\hline
\end{tabular}




\section{Findings}

This study sets out to answer two research questions which are listed in the introductory section above. The findings will attempt to answer the two questions using the themes generated from the data as guides. Direct quotes will be used to present the findings and the figure below reminds us of the themes that will be incorporated into the findings and discussions. Also note that the items on the figure were clustered by coding similarities such that themes with convergent ideas have similar colours.

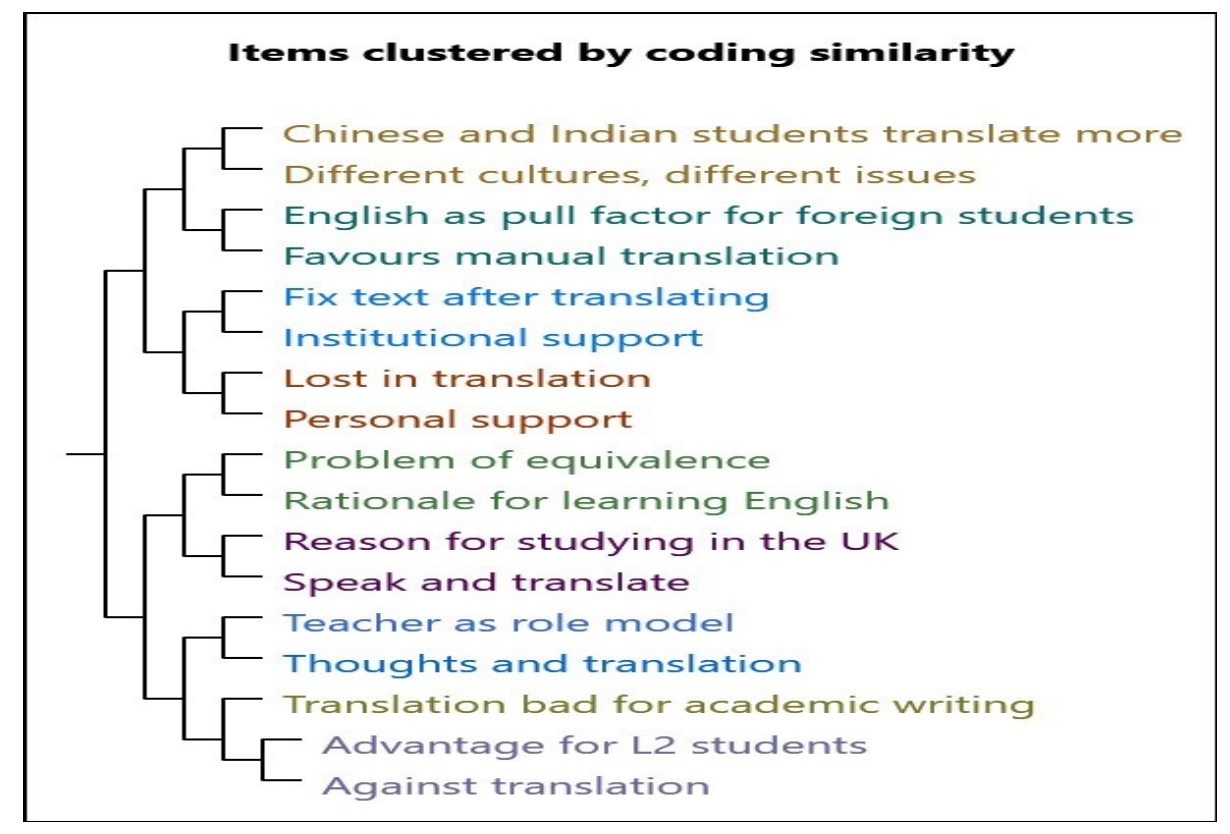

Figure 2. Themes Incorporated into the Findings

\subsection{How are Students' Academic Writings Affected by MT?}

The data revealed that all four lecturers interviewed in this study were unanimously against students' use of MT for academic purposes, although they acknowledged that language was a significant barrier for some students. One of the reasons advanced was that when students translate from ST to TT, the essay ends up not making much sense (Arnold et al, 1994), resulting in students getting 'lost in translation'. Two lecturers touched on the issue of sense-making though from different angles as seen on the following quotes:

We had a student who cheated by using synonyms and just changed the words of a text. However, it ended up not making any sense in the context of a law subject. For a word like state, he will use affairs, and it will mean nothing in the context. I had another student who translated things like that, and the essay was completely useless. I couldn't read it at all (Dr Evelyn).

... But when you read it, it doesn't make sense grammatically because the student is kind of directly translating in his or her mind, from the mother tongue into English (Prof. Felix). 
In the above quote, Dr Evelyn mentioned two possible issues with the student's translation: The first is that translation like the one done by the said student can be equated to cheating. The second is that word-for-word translation is problematic and can result in senseless TT. Dr Evelyn's assertion is supported by Munday (2016) who argues that word-for-word approach follows closely the form of ST, consequently producing an absurd translation which cloaks the sense of the original. Instead, he seems to advocate a sense-for-sense approach which allows the sense or content of the ST to be translated (Arnold et al, 1994). Prof. Felix on the other hand, thinks that direct translation from ST to TT can lead to grammatical errors. However, he was referring to translation made in the mind not with the machine. He believes that some students have the tendency of trying to understand things in their first language before writing it down in English. Thus, those students are writing in English, but are subconsciously reflecting in the source language. This, according to Prof. Felix is the reason why some students produce texts that do not make sense. The relationship between language and thought (Chomsky, 2004; Cook, 2015), was re-echoed by Dr Evelyn when she said, "I always tell students to think in the language they will use to answer questions, so they should think in English". The link between thinking in the ST and writing in the TT (Woodall, 2002) is an unexpected and a novel finding which deserves further research.

All the lecturers interviewed postulated that writing directly in the target language is beneficial to students whom English is not their first language. They contended that the more students practice writing in the target language, the better they consolidate their skills in the TT. The lecturers explicitly rejected the act of students using machine translation. One lecturer insisted that part of the reasons why some students come to study in the UK is to acquire English language skills and machine translation betrays that purpose. He argued that if students decide to stay and work in the UK after graduating, they will need language skills which they must acquire now. According to him, it is not justifiable to have a certificate from an English university without being able to write a "simple report" in English.

I think part of the reason why foreign students would want to come to the UK is the quality of the education that we offer, but most importantly is the English language. To go on then and instruct students to write in their local language and then just translate into English, they will not be achieving their core objective of why they are here in the first place (Dr Linus).

The best way is to write directly in English because when you start writing and translating, I don't think it really helps you to learn the language. (Prof. Felix).

Another problem with machine translation identified by the interviewees was double tasking. At least two interviewees noted that some students use translation devices in class, while others take notes in their first language. Double tasking not only distracts students from following the lecturers but could also slow down their understanding of the lesson as evident in the following quote.

I have seen some of them use translators in class. Some of them are taking notes in Chinese which is fine. But if you are using a translator in class, how quickly are you following the lessons? (Dr Julius). 
Dr Julius further explained that some students even speak to the device and it translates, which they then copy and email to themselves. When this is done, the translated text becomes obvious. All lecturers interviewed claimed that they could easily tell the differences between text that was written and translated, and text that was translated from verbal speech. The problem of equivalence (Pym, 1997) also emerged from the data as one lecturer acknowledged that some Chinese students realised that there were some key words that could not be translated into English. Arnold et al. (1994) gave a similar example of the problem of equivalence when a machine translated the French phrase Les soldats sont dans le café as 'The soldiers are in the coffee' (pp. 4-12). This should have read: The soldiers are in the coffee shop.

Despite these firm rejections of students' usage of MT, some lecturers were willing to compromise. In fact, they even suggested other ways by which students can employ translation which will be beneficial to them, and acceptable to the lecturers. For instance, the idea of post-editing (O'Brien et al, 2014) was heralded as a way of solving the limitations of MT.

If they really want to do it properly, they should try to fix it after translating it. If they are going to submit it the same way that the smart phone application has translated, then it is not going to be good (Dr Julius).

The post-editing must be done by the student and not by a software as this too can be inaccurate, he argued. The literature does not support this argument. For instance, research conducted by Depraetere et al (2014), did not find any significant differences between human post-editing and software post-editing of MT. Dr Julius added that:

If the text is written down in the first language and then translated rather than spoken and translated, then its going to be better (Dr Julius).

This proposition was replicated by Dr Linus as follows:

If they write themselves in the local language and then try to translate it into English, that is part of the process of learning English language (Dr Linus).

\subsection{What can be Done to Redress Students' MT Hitches?}

Post-editing has been suggested as a possible solution to address MT hitches if students must use it. We have equally seen that there was a strong rejection of MT by all lecturers involved in this study. This section addresses the support provided by lecturers and their institutions to help students whom English is not their first language. Therefore, it is assumed here that the lack of adequate support with language and writing skills could be one of the reasons why students resort to MT.

\subsubsection{Personal Support}

The lecturers interviewed said they provide some form of support to students whom English is not their first language. Some ask students to bring in their draft and go through everything with them, correcting mistakes and giving direct verbal feedback. Some use track changes on 
Microsoft word to correct students' grammar and give them feedback.

I encourage them to show me the second draft and even the third one before submission. That does make a difference when you go through these things with them. (Dr Julius)

I use something like track-changes on Microsoft word to correct their grammar and explain everything. Sometimes they come into my office and I give them support as well (Dr Linus)

A lecturer also explained that cultural backgrounds affect students' writing. From experience, he has come to understand that students from diverse cultural background have different issues with their academic writings, and he tries to address them accordingly. For example, he posited that Chinese and Indian students are more likely to use machine translation than 'African' students. Thus, he tries to provide them support in terms of "settling in and cultural orientation". Another lecturer insisted that as role models, teachers should examine their own English first, especially if they are from a non-English speaking country. According to him, teachers cannot ask students to be perfect in English while they themselves are not proficient. Simplifying the notes given to students, making it less verbose and more readable can benefit students whom English is not their first language. Providing one-to-one support to students whom English is not their first language was deemed vital. However, if that was not possible, lecturers should signpost students to the appropriate department where they will receive help with their writing skills.

\subsubsection{Institutional Support}

In terms of intuitional support, it was reported that some universities have writing mentors who are normally based in the university's library. Writing mentors provide one-to-one sessions to students. They discuss a range of academic skills with students. They show students how to structure their work, how to paragraph, reference properly, do critical thinking, and how to answer questions. Writing mentors guide students to do all the above with practical examples. Another university has a department called "student experience" where there is a language section that helps students with their writing skills.

A lecturer asserted that the foundation route was a good opportunity for students whom English is not their first language. When students get into university through the foundation route, they are not only learning their core discipline, but also learning how to write in proper English. When students exit the foundation route and start an undergraduate course, they are proficient in English and maths, and understand the basics of their core discipline.

One university has a unit which is called 'wiser'. They are there to help all students, but specifically to help students whom English is not their first language. For example, if students think they are struggling with the structure and the grammar of their assignment, they could book an appointment and have a one-to-one talk with a 'wiser' staff. They show students how to structure their work and grammar.

Finally, some institutions provide in-sessional course to students whose first language is not 
English. They provide this course yearly, usually during summer before the commencement of the academic year in September. While a lecturer was proud that his university provided this course that helps non-English speaking students, another was frustrated that his university was not doing the same thing.

I am sure you will see quite a few lots of foreign students roaming around here. They are taking the in-sessional course before their courses start. That is the official support (Prof Felix).

...But again, that should be earlier on before they get into the course. Try and sort out those students that don't have the required skills, give them a refresher course over summer before they get into the program (Dr Linus).

\section{Discussion}

This study has revealed that MT usage by students is not appreciated by lecturers despite evidence from the literature suggesting that MT can be beneficial. At least, in the context of this study, lecturers were strongly opposed to this phenomenon. The main reasons advanced for this rejection were, first, that students are 'lost in translation' when they use MT. Second, that MT does not help students learn or consolidate their skills in English. Third, that MT distracts students in class, especially when they are translating during the lessons. This distraction implies that students may not effectively follow the lessons and end up not understanding what has been taught. Fourth, that MT can waste students' time which could have been used more judiciously. Due to these disadvantages, lecturers suggested that, if students must use MT, they should do manual post-editing before submission. Some students use MT to do word-for-word, rather than reason-for-reason translation. Reason-for-reason translation requires real world knowledge and the technical knowledge of the text's subject matter (Arnold et al, 1994). Thus, efforts at producing MT systems which do so are still in their infancy (Poibieu, 2017). Other students realised that they could not find the befitting equivalence (Garcia-Landa, 2000; Pym, 1997) of source language in the target language. In both cases, the students produced texts that do not make sense to the lecturers, thereby risking loss of marks and potentially failure in the assignment.

The data also disclosed that both lecturers and institutions provided some form of support to students whom English is not their first language. At a personal or informal level, tutors gave students the opportunity to send or bring their drafts for review prior to submission. Some were willing to read a second and even a third drafts, correcting grammatical errors and giving both verbal and written feedback. We do not know whether students who used MT took advantage of lecturers' offer to read drafts, or whether sending a draft to the lecturer had any effect on minimising the use of MT. This was beyond the scope of this paper.

Apart from personal or informal support, institutional supports were readily available to students whom English is not their first language. For instance, some institutions provide in-seasonal sessions where new international students can study language skills prior to commencing their course. Other institutions have writing mentors in the library who assist 
non-English speaking students with their academic writing skills. Yet, other institutions have programs like the 'wiser' and the foundation route which are beneficial to students struggling with their English skills. However, we do not know whether those students who used MT took advantage of these programs, or what impact such programs made in minimising students' usage of MT. Again, these dimensions were beyond the remit of this research.

\subsection{Recommendations}

This study has raised an important issue which seem to be trending in higher education, but to which little attention has been paid. The fact that all four lecturers from different universities raised this issue and seriously opposed it means it should not be pushed under the carpet. It is a problem that universities need to address and so this study recommends the following:

- That universities should quickly address the problem of machine translation and see how that affects students' academic achievement.

- Having evaluated the impact of MT on students' outcome, universities should institute a policy on how to officially incorporate MT into teaching or discourage its use.

- Lecturers should be part of the conversation and any policy reached on this issue must take lecturers' views into consideration.

- Universities should do more to sensitize students whom English is not their first language about the support available to them which they might not be aware of.

- In-sessional language courses have helped students with their language skills prior to commencing their course, so this should be available in all universities.

\subsection{Limitations and Looking Forward}

This was a small-scale study that sampled the perspectives of four lecturers only. Those views were not analysed by gender, race, personal values, religion, or nationality. Thus, their views can be said to be subjective and may not reflect the views of other lecturers who work in the same university. This mean that we cannot generalise the findings of this research to all the lecturers in the universities where the interviewees work. However, this research was never intended to generalise findings, but to understand the phenomenon through an in-depth study of the participants' perspectives.

A novel and unexpected outcome of this research was the attempt by a participant to relate the problems of translation to that of thought. According to Prof Felix, some students think in their first language, translate in their minds, and write down the text in their second language. This to him, was a reason why students get lost in translation. Although this proposition was not directly related to MT, it raised an important topic for future research. Future researchers may want to investigate the relationship between thought and translation and how thinking in SL affect translation in TT. Another aspect that may require further investigation is whether providing support for students with reviewing their drafts, correcting mistakes, and providing feedback minimises their usage of MT. Finally, future research may be interested to investigate whether students who take advantage of institutional supports with writing skills 
make less use of MT than those who do not.

\section{References}

Arnold, D. J., Balkan, L., Meijer, S., Humphreys, R. L., \& Sadler, L. (1994). Machine Translation: An Introductory Guide. NCC Blackwell Ltd.

BERA. (2018). Ethical Guidelines for Educational Research. London: British Educational Research Association. Retrieved from https://www.bera.ac.uk/publication/ethical-guidelines-for-educational-research-2018

Bowker, L., \& Fisher, D. (2010). Computer-aided translation. In Y. Gambier, \& V. L. Doorslaer (Eds.), Handbook of Translation Studies (pp. 60-65). John Benjamins Publishing Company.

Bryman, A. (2004). Social Research Methods (2nd ed.). Oxford University Press.

Bryman, A. (2016). Social Research Methods (5th ed.). Oxford University Press.

Chomsky, N. (2004). Language and Thought. (6th ed.). Moyer Bell.

Cohen, A. D., \& Brooks-Carson, A. (2001). Research on direct versus translated writing: Students' strategies and their results. The Modern Language Journal (Boulder, Colo.), 85(2), 169-188. https://doi.org/10.1111/0026-7902.00103

Cook, V. (2015). Discussing the language and thought of motion in second language speakers: Discussing the language and thought of motion. The Modern Language Journal, 99(S1), 154-164. http://doi.org/10.1111/j.1540-4781.2015.12184.x

David, M., \& Sutton, C. D. (2004). Social Research: The Basics. SAGE Publications, Inc.

Depraetere, I., De Sutter, N., \& Tezcan, A. (2014). Post-edited quality, post-editing behaviour and human evaluation: A case study. In S. O'Brien (Ed.), Post-editing of machine translation: Processes and applications (pp. 78-108). Cambridge Scholars Publishing.

Garcia-Landa, M. (2000). Translation theory and the problem of equivalence. Hermēneus. Revista de Traducción e Interpretación, 2. Retrieved from https://core.ac.uk/download/pdf/211092995.pdf

GDPR.EU (2020). General Data Protection Regulations (GDPR). Retrieved from https://gdpr.eu/tag/gdpr/page/2/

Groves, M., \& Mundt, K. (2015). Friend or foe? google translate in language for academic purposes. English for Specific Purposes, 37, 112-121. http://doi.org/10.1016/j.esp.2014.09.001

Hatim, B., \& Munday, J. (2004). Translation: An advanced resource book. Routledge.

Hartley, A. (2009). Technology and translation. In J, Munday (Ed.), The Routledge Companion to Translation Studies, (pp. 106-27). Routledge. 
Government, H. M. (2020). Data Protection Act 1998. The National Archives. Retrieved from https://www.legislation.gov.uk/ukpga/1998/29/contents

Källkvist, M. (2013). Languaging in translation tasks used in a university setting: Particular potential for student agency? Languaging in translation tasks used in a university setting. The Modern Language Journal, 97(1), 217-238. http://doi.org/10.1111/j.1540-4781.2013.01430.x

Kay, M. (1997). The proper place of men and machines in language translation. Machine Translation, 12(1/2), 3-23. http://doi.org/10.1023/A:1007911416676

Lee, S. M. (2020). The impact of using machine translation on EFL students' writing. Computer Assisted Language Learning, 3(33), 157-175. https://doi.org/10.1080/09588221.2018.1553186

Lee, S., \& Briggs, N. (2021). Effects of using machine translation to mediate the revision process of Korean university students' academic writing. ReCALL, 1(33), 18-33. http://doi.org/1017/S0958344020000191

Munday, J. (2016). Introducing Translation Studies: Theories and Applications (4th ed.). Routledge.

Nchindia, C. A. (2020). Black and ethnic minority academics' perspectives on intercultural interaction in UK universities: Beyond racialization. International Journal of Education, 4(12), 49-72. http://dx.doi.org/10.5296/ije.v12i4.17790

Nida, E. (1964). Toward a Science of Translating. E. J. Brill

Nida, E., \& Taber, C. (1969). The Theory and Practice of Translation. E. J. Brill.

O'Brien, S., Balling, L. W., Carl, M., Simard, M., \& Specia, L. (2014). Post-editing of machine translation: Processes and applications. Cambridge Scholars Publishing.

Panter, M. (n.d.). Translating Academic Writing: Human vs. Machine. AJE Scholar. Retrieved from https://www.aje.com/arc/translating-academic-writing-human-vs-machine/

Poibeau, T. (2017). Machine translation. The MIT Press.

Pym, A. (2007). Natural and directional equivalence in theories of translation. Target, 2(19), 271-94. https://doi.org/10.1075/target.19.2.07pym

Rensburg, A. V., Snyman, C., \& Lotz, S. (2012). Applying Google Translate in a higher education environment: Translation products assessed. Southern African Linguistics and Applied Language Studies, 4(30), 511-524. https://doi.org/10.2989/16073614.2012.750824

Stander, M. (2020). Strategies to help university students avoid plagiarism: a focus on translation as an intervention strategy. Journal of Further and Higher Education, 2(44), 156-169. http://doi.org/10.1080/0309877X.2018.1526260 
Woodall, B. R. (2002). Language-switching: Using the first language while writing in a second language. Journal of Second Language Writing, 11(1), 7-28. https://doi.org/10.1016/S1060-3743(01)00051-0

Waddington, C. (2001). Different methods of evaluating student translations: The question of validity. Journal des traducteurs, 2(46), 311-325.

Wang, L. (2003). Switching to first language among writers with differing second-language proficiency. Journal of Second Language Writing, 12(4), 347-375. https://doi.org/10.1016/j.jslw.2003.08.003

Werner, K. (1995). The concept of equivalence and the object of translation studies. Target, 2(7), 191-222. https://doi.org/10.1075/target.7.2.02kol

Zanettin, F. (2009). Corpus-based Translation Activities for Language Learners. The Interpreter and Translator Trainer, 2(3), 209-224. https://doi.org/10.1080/09588221.2018.1553186

Zhao, N., Gao, F., \& Yang, D. (2018). Examining student learning and perceptions in social annotation-based translation activities. Interactive Learning Environments, 26(7), 958-969. http://doi.org/10.1080/10494820.2017.1421564

\section{Copyright Disclaimer}

Copyright for this article is retained by the author(s), with first publication rights granted to the journal.

This is an open-access article distributed under the terms and conditions of the Creative Commons Attribution license (http://creativecommons.org/licenses/by/3.0/). 